\title{
Comparison between Comfort-Behavior and Ramsay scales in a pediatric intensive care unit*
}

\author{
Comparação entre as escalas de Comfort-Behavior e Ramsay em uma unidade de terapia \\ intensiva pediátrica
}

Marcella Zuliani Lopes Soares ${ }^{1}$, Andréa Gomes da Costa Mohallem², Simone Brandi ${ }^{1}$, Mariana Lucas da Rocha Cunha ${ }^{2}$

${ }^{*}$ Received from the Nursing School, Israelite Hospital Albert Einstein, São Paulo, SP, Brazil.

- Nursing Graduation Course Conclusion Paper.

DOI 10.5935/1806-0013.20140007

\section{ABSTRACT}

BACKGROUND AND OBJECTIVES: Studies have tried to compare sedation scales, however time spent with their application has not been studied. This study aimed at checking sedation level of patients admitted to the pediatric intensive care unit according to Comfort-Behavior and Ramsay scales, comparing sedation score and time spent to apply both scales.

METHODS: This prospective study has involved patients aged from one day of life until 18 incomplete years, admitted to the pediatric intensive care unit, submitted or not to mechanical ventilation, who needed analgesic and/or sedative therapy and after acceptance of legal representatives. Exclusion criteria were patients under neuromuscular blockers and in process of extubation. A checklist developed by the authors was used to collect dada. Data were collected in four observations per patient (14h, $16 \mathrm{~h}, 18 \mathrm{~h}$ and $20 \mathrm{~h}$ ), in a total of 48 observations. Sample was made up of six patients.

RESULTS: In 22 observations there have been high sedation levels in both scales. Moderate sedation was found in one observation for both scales. No evaluation has shown low sedation levels. Mean time using Comfort-Behavior scale was longer as compared to Ramsay scale ( $\mathrm{p}=0.019)$. There has been no significant variation among patients and among observers.

CONCLUSION: Evaluated scores had similar results; however mean time for Comfort-Behavior scale was longer than for Ramsey scale without variation among patients or among observers.

Keywords: Deep sedation, Method, Nursing, Pain measurement, Pediatric intensive care unit, Physiological monitoring.

1. Israelite Hospital Albert Einstein, Pediatric Intensive Care Unit, São Paulo, SP, Brazil.

2. Israelite School of Health Sciences Albert Einstein, Israelite Hospital Albert Einstein, São Paulo, SP, Brazil.

Submitted in December 19, 2012.

Accepted for publication in February 17, 2014

Conflict of interests: none.

Correspondence to:

Marcella Zuliani Lopes Soares

Rua Bartira 485/71 Bloco 1 - Perdizes

05009-000 São Paulo, SP, Brasil.

E-mail: marcellasoares803@hotmail.com

(C) Sociedade Brasileira para o Estudo da Dor
RESUMO

JUSTIFICATIVA E OBJETIVOS: Estudos buscaram comparar escalas de sedação, porém o tempo gasto na sua aplicação náo tem sido pesquisado. Os objetivos deste estudo foram verificar o nível de sedação de pacientes internados na unidade de terapia intensiva pediátrica de acordo com as escalas de Comfort-Behavior e Ramsay, comparando o escore de sedação e o tempo gasto na aplicação das duas escalas.

MÉTODOS: Este estudo prospectivo englobou os pacientes a partir de um dia de vida até 18 anos incompletos, internados na unidade de terapia intensiva pediátrica, submetidos à ventilação mecânica ou não, que necessitaram de terapia analgésica e/ou sedativa e com aceite do responsável legal. Não foram incluídos pacientes em uso de bloqueador neuromuscular e em processo de extubaçáo. Para o levantamento dos dados, foi utilizado um formulário do tipo Check List, elaborado pelas autoras. A coleta de dados foi realizada em quatro observaçóes por paciente (14h, 16h, $18 \mathrm{~h}$ e $20 \mathrm{~h})$, totalizando 48 observaçóes. A amostra foi composta por seis pacientes.

RESULTADOS: Em 22 observaçóes foram constatados níveis altos de sedação em ambas as escalas. Níveis moderados de sedação foram encontrados em uma observação de ambas as escalas. Em nenhuma das avaliaçóes foram observados níveis baixos de sedação. O tempo médio usando a escala de Comfort-Behavior foi maior que o da escala de Ramsay ( $p=0,019)$. Não houve variação significativa entre os pacientes assim como entre os observadores.

CONCLUSÃO: Os escores avaliados apresentaram equivalência nos resultados, entretanto o tempo médio usando a escala Comfort-Behavior foi maior que o da escala de Ramsay, não tendo sido encontrada variaçáo entre os pacientes, assim como entre os observadores.

Descritores: Enfermagem, Mensuração da dor, Método, Monitorização fisiológica, Sedação profunda, Unidade de terapia intensiva pediátrica.

\section{INTRODUCTION}

In a pediatric intensive care unit (PICU), patients are constantly exposed to severe psychic impact caused by anxiety, fear, sleep and wake disorders, immobility in bed, uncomfortable 
handling and invasive procedures, such as tracheal intubation, venous or arterial punctures and chest drainage. A major objective of health professionals assisting children admitted to the PICU is to carry out treatments implying the less possible aggression to prevent further physical and emotional distress for children and their relatives ${ }^{1,2}$.

This scenario of severe psychic impact added to the need for mechanical ventilation support, is among the most common indications for the use of analgesia and/or sedation for these patients. Analgesia and sedation, in addition to optimizing the treatment, provide comfort, control pain and decrease the level of anxiety and agitation of these patients ${ }^{1,2}$.

Notwithstanding the benefits of vasoactive and analgesic drugs for critically ill patients, the excessive use is associated to increased hospitalization time, risk of infections and mortality rate, in addition to the probability of developing withdrawal symptoms when they are interrupted, which may vary in quality and intensity ${ }^{1-4}$.

The use of sedation/analgesia should be carefully evaluated by the medical team by means of reached sedation levels, to use the lowest possible dose and minimize the risk of adverse events, giving priority to optimal sedation. Deep sedation should only be maintained when needed, thus decreasing mechanical ventilation support time and consequently hospitalization costs. It is also recommended to avoid insufficient sedation which would cause distress to patients in addition to putting at risk their safety ${ }^{1-4}$.

Current trend is toward tailoring patients' treatment, which makes critical the continuous evaluation of pain, the monitoring of sedation and analgesia. The Brazilian Consensus for Sedation and Analgesia in Intensive Care Units (ICU) suggests that periodic evaluation of intensity and quality of analgesia and sedation should be incorporated to the clinical monitoring routine of adult ICUs 5 .

Pain is a subjective experience and in the pediatric setting children should be evaluated by means of adequate tools and treated according to their age group, their cognitive development and their clinical conditions. For these reasons, evaluation is far more complicated and difficult, especially for patients submitted to sedation and mechanical ventilation (MV), because in many situations it is impossible to distinguish between pain and anxiety and both should be simultaneously treated. It is up to the nursing team to be prepared and provide a humanized care $^{1,6}$.

Clinical scales are the most common tools used by nurses to monitor sedation levels and they offer parameters for the integration of information between nurses and the medical team. This information helps them to daily redefine and adjust drug doses. Major scales currently being used are Ramsay sedation scale (R), Richmond sedation agitation scale and ComfortBehavior (CB) scale, being the former and the latter the most widely used in pediatrics ${ }^{1-4}$.

It is possible to find in the literature comparisons between $\mathrm{R}$ and $\mathrm{CB}$ scales, showing equivalence in the evaluation of sedation levels of critically ill patients. There is also a study analyzing $\mathrm{CB}$ scale and Motor Activity Evaluation scale (MAE) as a valid tool to be used in children submitted to MV. However, studies do not mention the time spent to apply such scales ${ }^{2,3}$. There are no studies in the literature specifically comparing $R$ and CB scales.

Sedation level evaluation with the R scale was proposed in 1974 and is based on clinical criteria for its classification, using the numbers 1 to 6 to score anxiety, agitation or both, until total absence of patient's response. It requires contact with patients since it is necessary a light glabellar touch or auditory sound stimulation, depending on patients' condition. Observed signs are: excessively high sedation levels with Ramsay 5 or 6; adequate sedation levels needing observation with Ramsay 2 to 4; inadequate or insufficient sedation levels with Ramsay $1^{1,2}$. CB scale, described in 1992, is an observational tool specifically developed for children under MV. It analyzes behavioral and physiological parameters after two minutes of observation and considers variables such as: mean blood pressure (MBP), heart rate (HR), muscle tone, face tone, level of consciousness, agitation/relaxation, respiratory and physical movements. In 2005, the scale was simplified. Physiological variables were eliminated and it was called CB. This scale is related just to behavioral variables ${ }^{1,3,7,8}$.

It is clear that such scale cannot be used together with neuromuscular blockers and includes variables such as MBP and HR, which change due to other factors and make the evaluation subjective ${ }^{1,3}$.

The following were as suggested as cutoff points for the score found: a score between 6 and 10 would correspond to over-sedation or deep sedation; score equal to or above 23 , insufficient sedation; and for the intermediate range between 11 and 22, moderate sedation ${ }^{3,7}$.

Considering the importance of evaluating sedation levels of children admitted to the PICU by nursing professionals, this study aimed at comparing $\mathrm{CB}$ and $\mathrm{R}$ scales with regard to sedation scores and time spent to apply them.

\section{METHODS}

His is a descriptive-exploratory, prospective field study, by non participative observation with quantitative data analysis. The study was carried out in the PICU of the Israelite Hospital Albert Einstein, a large private tertiary hospital located in the south zone of the city of São Paulo.

Inclusion criteria were patients from 1 day of life until 18 incomplete years of age, admitted to the PICU, submitted or not to MV, who needed analgesic and/or sedative therapy and whose legal representatives would agree with their participation in the study. Exclusion criteria were patients under neuromuscular blockers and in process of extubation.

A checklist developed by the authors was used for data collection and included the following items: data collection date; date of admission to the unit, children identification data (gender and age); medical diagnosis; clinical and surgical background; MV mode; analgesic and/or sedative drugs. Scores of CB and R scales were also included in this tool with their corresponding meanings; time spent to apply each one, which was measured 
with a stopwatch; presence of pain and whether sedation had to be modified.

Data were collected between August and September 2012 from 02:00 pm to 08:00 pm, in a total of four observations per patient (02:00, 04:00, 06:00 and 08:00 pm). Each patient was evaluated for just one day by a different professional at each time. The purpose was preventing previous evaluation to influence next. Both scales were sequentially applied.

Nursing professionals, nurses and nursing technicians have applied the scales at bedside, together with the routine of checking vital signs, scores for each scale were recorded and time spent for the application of each one, separately, was measured. A checklist was filled out for every patient. Information was recorded as from non participative observation of the investigator, with the measurement of time spent to apply each scale, which was done in patient's room.

The research children would participate in was explained before the evaluation and the Free and Informed Consent Term (FICT) was delivered to be signed by children's legal representatives, in case they agreed with their participation.

Checklist data were submitted to descriptive statistical analysis and results were presented in absolute figures by means of tables and figures.

This study was approved by the Research Ethics Committee HIAE (CAAE 04332712.6.0000.0071 - 2012).

\section{RESULTS}

Participated in the study six patients being three males and three females. Ages have varied from 30 days to 6 years and 5 months, being two children below one year, two between 1 and 3 years and two above 3 years of age.

Children had more than one diagnosis and most frequent were: respiratory disease (bronchopneumonia, respiratory failure and bronchiolitis), followed by heart disease (pericardial effusion, atrioventricular septum defect and atrial canal persistence). Septic shock diagnosis was found in two children and polytrauma with brain trauma and pulmonary contusion was found in one child. Only two patients had clinical background being that both had Down syndrome.

The combination of midazolam and fentanyl was the most widely used sedation and analgesia regimen ( 5 patients of the sample), with or without other sedative drug: propofol, chloral hydrate or thiopental. Just one child has received only chloral hydrate for sedation and no analgesic drug.

As to MV modality, half the cases used controlled pressure (CP) and the other half synchronized intermittent mandatory ventilation (SIMV).

Forty-eight observations were recorded, being 24 from the use of CB scale and 24 from R scale. Mean score of CB observations was 7.3 and of $\mathrm{R}$ observations was 5.9 (Table 1), corresponding to deep sedation in both scales.

High sedation levels were found in 22 observations for both scales: $\mathrm{CB}$ with score between 6 and 10 and $\mathrm{R}$ with score $\geq 5$. Moderate sedation levels were found in one observation for both scales: CB between 11 and 20 and R between 2 and 4. No evaluation has shown low sedation levels (Figure 1).

Scales have disagreed in just one observation. It has to be recorded, however, that scores were at the limit of the change in sedation pattern: score 5 by $\mathrm{R}$ scale (deep sedation) and score 11 by $\mathrm{CB}$ scale (moderate sedation). Score 10 by CB would mean deep sedation and score four by $\mathrm{R}$ scale would indicate moderate sedation.

Mean time to apply each scale was 63 seconds for CB and 30 seconds for $\mathrm{R}$, resulting in a difference of 33 seconds, as shown in figure 2 .

Analysis of variance (ANOVA) test, which considered scale, patient and observer variables as factors, has shown that mean times spent to apply each scale are significantly different $(p=0.019)$. So, one may conclude that mean time for $\mathrm{CB}$ scale is significantly longer as compared to $\mathrm{R}$ scale. Test has also shown that there is no significant variation among patients $(\mathrm{p}=0.629)$ as well as among observers $(\mathrm{p}=0.300)$.

Standard deviation of CB scale ( 46.86 seconds) is almost twice the standard deviation of $\mathrm{R}$ scale $(25.29$ seconds). So, in addition to $\mathrm{CB}$ mean time being longer than $\mathrm{R}$ time, $\mathrm{CB}$ times have higher variability around the mean as compared to $\mathrm{R}$ times. Interval (mean \pm SD) for $\mathrm{CB}$ was 16 to 110 seconds and for $\mathrm{R}$ it was 5 to 55 seconds.

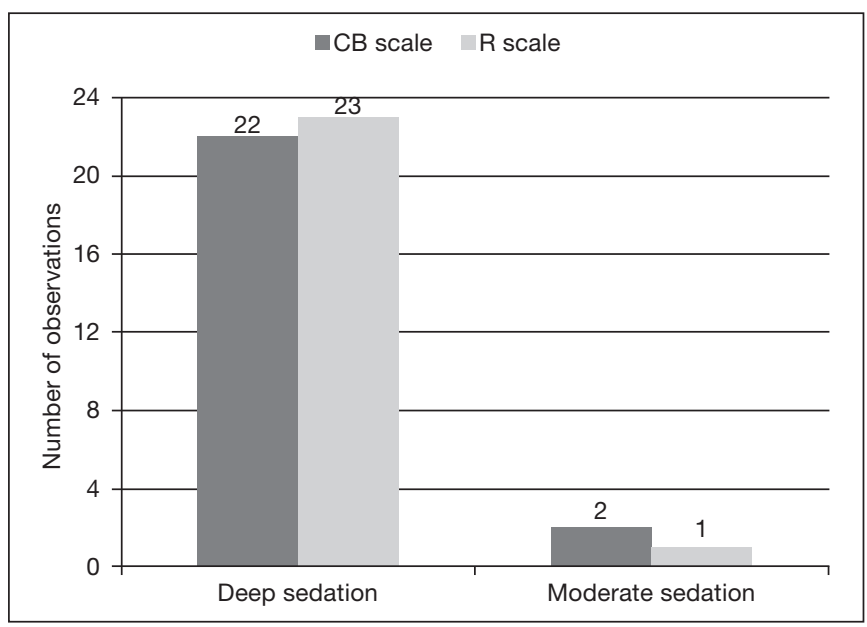

Figure 1. Sedation levels found in observed samples according to Comfort-Behavior and Ramsay scales

CB: Comfort-Behavior; R: Ramsay.

Table 1. Mean sedation score obtained with the application of Comfort-Behavior and Ramsay scales

\begin{tabular}{lccccccc}
\hline Scales & Sample 1 & Sample 2 & Sample 3 & Sample 4 & Sample 5 & Sample 6 & General Mean \\
\hline CB & 7.8 & 7.3 & 8.3 & 7.8 & 7.0 & 6.0 & 7.3 \\
R & 5.8 & 6.0 & 6.0 & 5.5 & 6.0 & 6.0 & 5.9 \\
\hline
\end{tabular}

CB: Comfort-Behavior; R: Ramsay. 


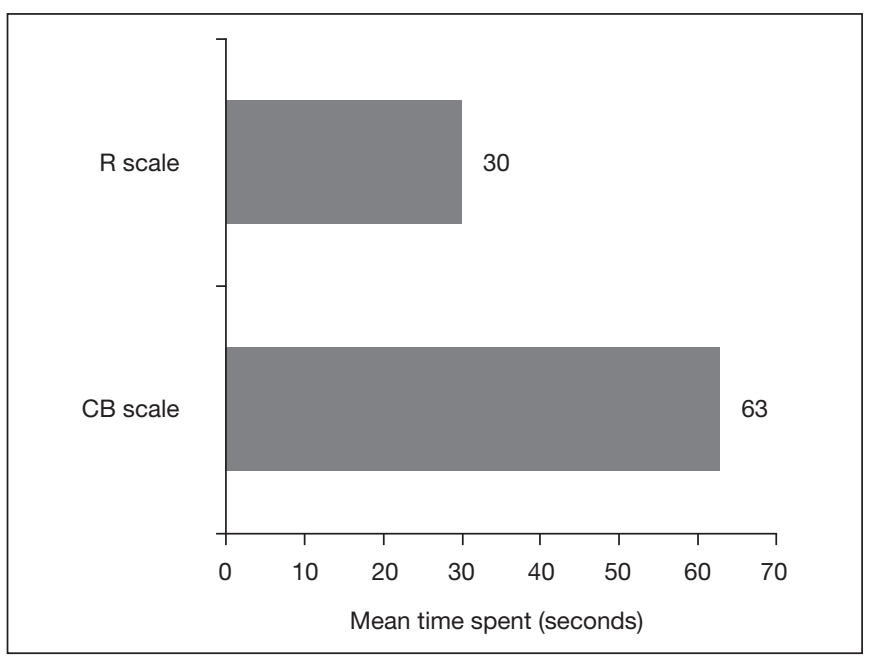

Figure 2. Mean time spent to apply each scale

CB: Comfort-Behavior; R: Ramsay.

Pain could interfere with scales results and, as a consequence, with reliability of data obtained. Pain was evaluated according to vital signs observation routine and simultaneously with scales application moments and no pain episode was observed.

\section{DISCUSSION}

Consensus for ICU sedation/analgesia indicate as sedatives midazolam and propofol, which were introduced in the clinical practice as from 1980 and remain as the most popular and studied drugs for sedation, and as analgesics opioids, being fentanyl the drug of choice? ${ }^{9}$ The same recommended drugs were found in our study.

Several studies report that sedation should be adapted to each child in each moment. There is a large variety of drugs available for sedation and analgesia for critically ill children and each one has advantages and disadvantages. There are few reviews and practical consensus guides about sedative/analgesics for critically ill children, and part of recommendations is based on experiences with adults ${ }^{1,5,9}$.

A Chinese study with children submitted to heart surgeries has focused on pain status and sedation level presented by them in the three consecutive postoperative days. Pain was evaluated with a complex scale analyzing face, legs, activity, weeping and consolability, and sedation was evaluated with CB scale. Results have shown that the use of analgesics and sedatives in the PICU was variable and that children had low pain scores, but high sedation rates, indicating that health professionals should address ways to improve postoperative pain and to manage sedation for this population ${ }^{10}$.

With regard to observation of pain, the North American Consensus for Sedation and Analgesia in ICU, defines that pain evaluation should be systematically documented and carried out with adequate scales for this population. After defining pain intensity, this consensus suggests revaluating analgesic therapy ${ }^{11}$. In our study, there has been no pain episode during scales application moments, with no need to revaluate the seda- tion/analgesic therapy.

With regard to sedation scales, a literature search and review of experience with PICU, developed in 2007, shows R scale as simple and fast to be applied, however, because it uses auditory and painful stimulations to evaluate children's response, its evaluation becomes subjective. With regard to CB scale, the study mentions that no painful stimulation is needed during its application; however it takes longer and is more complicated to be applied due to the analysis of different parameters ${ }^{1}$.

A recent systematic review ${ }^{12}$ has included 25 studies and has evaluated sedation reported by critically ill children under intensive care. Results have shown the use of 12 different sedation scales, with predominance of CB scale followed by $\mathrm{R}$ scale and other two scales. Six studies have used additional tools to scales, especially bispectral index (BIS). With regard to the level of sedation, it was shown that studies have differed in cutoff values for the scales, presenting optimal sedation in $57.6 \%$, excessive sedation in $31.8 \%$ and low sedation in $10.6 \%$ of observations. Recently, other methods complementary to scales are being developed to more objectively determine consciousness levels by analyzing electroencephalogram (EEG) characteristics. BIS is the most widely used; however it is not routine for most services, especially due to its high cost. BIS improves PICU sedation, preventing the risk associated to low and excessive sedation, it proposes a major advance for continuous monitoring of patients needing deep sedation and neuromuscular block, in addition to defining the classification of patients with moderate sedation levels because it continuously evaluates EEG changes offering a numerical measurement of the level of sedation, from zero (electric silence) to 100 (awake) $)^{1-3,13-15}$.

A different study ${ }^{3}$ developed in the PICU of a hospital of Porto Alegre has validated CB scale to the Portuguese language, has evaluated sedation levels of patients under MV and has compared its performance to motor activity evaluation scale (MAE), which was also being validated in this language for the pediatric population. After translating into Portuguese, scales were applied in a total of 116 observations and have shown patients with high sedation levels with the combination of midazolam and fentanyl. This trend was also found in our study in five out of six studied patients where high sedation levels by $\mathrm{CB}$ were found in 22 observations and by $\mathrm{R}$ scale in 23 observations.

As to most frequent diagnoses, there has also been agreement with our study, with emphasis to respiratory diseases in 22 out of 26 patients of the Porto Alegre study ${ }^{3}$, and in 4 out of 6 patients in our study.

Specifically regarding time, a Dutch study has checked CB scale performance with observation periods of 30 seconds and 2 minutes. A total of 133 PICU nurses have simultaneously applied the scales and the conclusion was that one should keep observation of 2 minutes for the scale evaluation to be more reliable and improved, time which is above the mean found in our study, as shown in Figure 2. There are no studies about time spent to apply R scale ${ }^{16}$.

The objective evaluation of sedation levels in the PICU is a challenge and even with the availability of several tools there is still no gold standard. The observation of low levels or ex- 
cessive sedation is often related to inadequate sedation levels evaluation ${ }^{17,18}$.

Since a publication showing that CB scale is a reliable alternative to existing others, it is finding increasingly more space in PICUs; however due to its complexity and extension, because it evaluates several parameters in a more detailed way, the look for alternatives is constant ${ }^{1,3,7,8}$.

With regard to scoring, $\mathrm{R}$ scale has some advantage over $\mathrm{CB}$ scale. The former uses numbers from 1 to 6 , being the highest score equivalent to the highest sedation level. In the latter, which varies from 6 to 3, the lower the score the higher the sedation level ${ }^{1-3,7}$. For this reason, the interpretation of CB scale results may be hindered. The initial consideration to choose $\mathrm{R}$ scale was based on its simplicity, considering that this would lead to a more consistent and reproducible analysis ${ }^{1,3,7}$.

\section{CONCLUSION}

The use of sedation scales to evaluate adequate sedation/analgesic therapy is a practice which is growing in settings such as PICUs. This study has as differential the comparison of the two presented scales and the evaluation of time spent to apply each one.

This study brings relevant conclusions and the subject addressed is of extreme interest for the pediatric community and for those interested in handling comfort and analgesia of critically ill patients. We suggest increasing the sample for a broader development of such important subject.

Based on data analysis, one may conclude that $\mathrm{CB}$ and $\mathrm{R}$ sedation scales scores had equivalent results, with predominance of deep sedation. In just one observation there has been disagreement between scales. It has to be recorded, however, that scores were at the limit of the change in sedation pattern. With regard to scales application, mean time spent for CB scale is significantly longer than for $\mathrm{R}$ scale.

\section{REFERENCES}

1. Bartomolé SM, López-Herce J, Freddi N. Sedação e analgesia em crianças: uma abordagem prática para as situaçóes mais frequentes. J Pediatric. 2007;83(2 Suppl):S71$-S 82$.

2. Mendes CL, Vasconcelos LC, Tavares JS, Fontan SB, Ferreira DC, Diniz LA, et al Escalas de Ramsay e Richmond são equivalentes para avaliação do nível de sedação em pacientes gravemente enfermos. Rev Bras Ter Intensiva. 2008;20(4):344-8.

3. Amoretti CF, Rodrigues GO, Carvalho PR, Trotta EA. Validação de escalas de sedação em crianças submetidas à ventilaçáo mecânica internadas em uma unidade de terapia intensiva pediátrica terciária. Rev Bras Ter Intensiva. 2008;20(4):325-30.

4. Cidoncha E, Mencía S, Riaño B, Urbano J, López-Herce J, Carrillo A. Valoración de la sedación em el niño crítico com ventilación mecánica durante la aspiración endotraqueal. An Pediatr (Barc). 2009;70(3):218-22.

5. Moritz RD, Souza RL, Machado FO. Avaliação de um algoritmo para a adequação da sedoanalgesia de pacientes internados em UTI e submetidos à ventilaçáo mecânica. Rev Bras Ter Intensiva. 2005;17(4):265-9.

6. Silva MS, Pinto MA, Gomes LM, Barbosa TL. Dor na criança internada: a percepção da equipe de enfermagem. Rev Dor. 2011;12(4):314-20.

7. Ista E, van Dijk M, Tibboel D, de Hoog M. Assessment of sedation levels in pediatric intensive care patients can be improved by using the COMFORT "behavior" scale. Pediatr Crit Care Med. 2005;6(1):58-63.

8. van Dijk M, Peters JW, van Deventer P, Tibboel D. The COMFORT Behavior Scale: a tool for assessing pain and sedation in infants. Am J Nurs. 2005;105(1):33-6.

9. Moritz RD. Sedação e analgesia em UTI: velhos fármacos, novas tendências. Rev Bras Ter Intensiva. 2005;17(1):52-5.

10. Bai J, Hsu L. Pain status and sedation level in Chinese children after cardiac surgery: an observational study. J Clin Nurs. 2012;22(1-2):137-47.

11. Sedation, analgesia, and neuromuscular blockade of the critically ill adult: revised clinical practice guidelines for 2002. Am J Health Syst Pharm. 2002;59(2):147-9.

12. Vet NJ, Ista E, Wildt SN, van Dijk M, Tibboel D, de Hoog M. Optimal sedation in pediatric intensive care patients: a systematic review. Intensive Care Med. 2013;39(9):1524-34

13. Sadhasivam S, Ganesh A, Robison A, Kaye R, Watcha MF. Validation of the bispectral index monitor for measuring the depth of sedation in children. Anesth Analg. 2006;102(2):383-8.

14. Mencía Bartolomé S, López-Herce Cid J, Lamas Ferreiro A, Borrego Domínguez R, Sancho Pérez L, Carrillo Alvarez A. Use of the bispectral Index in monitoring critically-ill children. An Pediatr (Barc). 2006;64(1):96-9.

15. Vázquez Martínez JL. Assessing sedation in PICU: clinical scales or BIS analysis? Minerva Anestesiol. 2012;78(3):286-7.

16. Boerlage AA, Ista E, de Jong M, Tibboel D, van Dijk M. The COMFORT behavior scale: is a shorter observation period feasible? Pediatr Crit Care Med. 2012;13(2):e124-5.

17. Lyden CM, Kramlich D, Groves R, Bagwell SP. Phase I: The development and conten analysis of the Pediatric Sedation Agitation Scale. Pediatr Nurs. 2012;38(5):278-84.

18. Litalien C, Jouvet P. Validation of a sedation scale for young mechanically ventilated children: A painful challenge? Pediatr Crit Care Med. 2006;7(2):183-4. 